\title{
GUARDING
} YOUR ASSETS

Anyone taking part in a contact sport should wear a mouthguard, according to new guidance from the British Orthodontic Society. Up to $39 \%$ of all dental injuries are sports related and one in four children will lose a tooth at some stage through sport, the guidance notes. It calls for the use of mouthguards in: American football, cycling, boxing, cricket, football, hockey, horse riding, ice hockey, skating, judo, kick boxing, lacrosse, martial arts, netball, roller skating, rounders, rugby, skateboarding, skiing and wrestling. The guidance also advises that special mouthguards are required for use with braces.

\section{COUNTDOWN TO COMPULSORY CPD}

From 1 August all DCPs will be required to complete and record a minimum of 150 hours CPD per five years, 50 hours of which should be verifiable. This should include verifiable CPD in medical emergencies (10 hours) per cycle, disinfection and decontamination ( 5 hours per cycle) and radiography and radiation protection ( 5 hours per cycle). Further details are available on the GDC website.

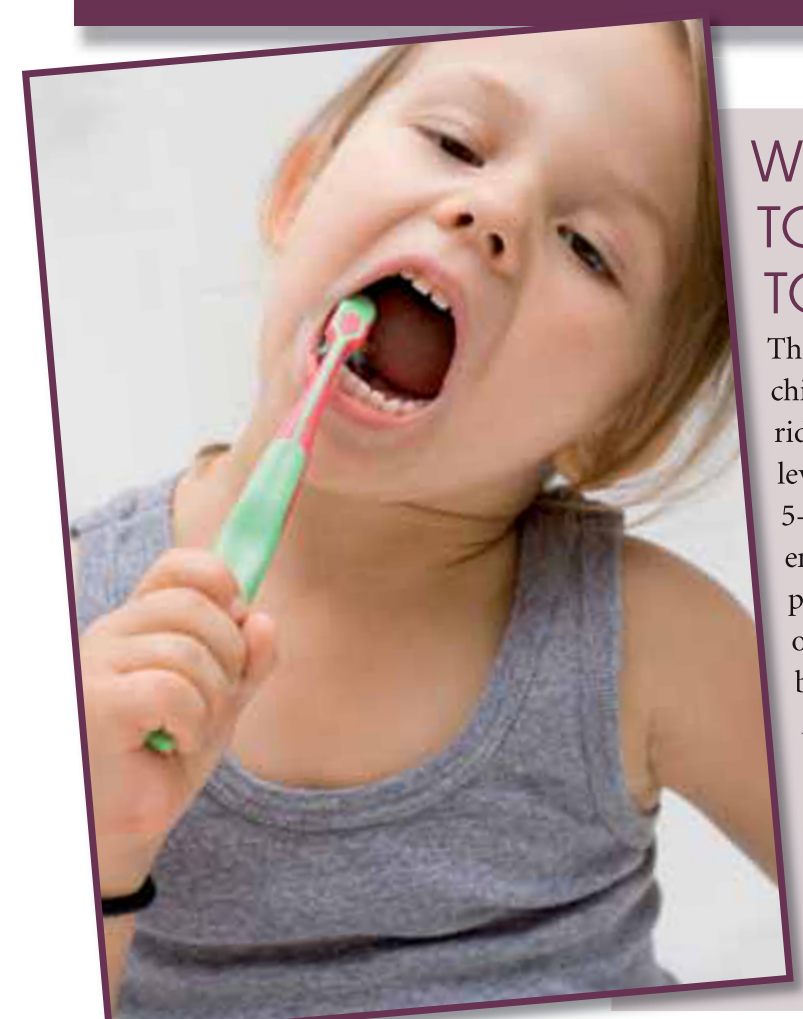

WELSH CHILDREN TO GET FREE \section{TOOTHBRUSHES}

The Welsh Assembly is planning to give all children in Wales free toothbrushes and fluoride toothpaste to counteract unacceptable levels of tooth decay. More than half of all 5 -year-olds in the principality have experienced tooth decay. Supervised toothbrushing programmes will be launched for 3-5 year olds, starting with pilot schemes in Denbigh and Conwy, North Wales, and Cardiff. Announcing the Designed to Smile programme, in March, Welsh health minister Edwina Hart said, 'Rates of tooth decay in Wales are unacceptable for what is almost a totally preventable disease. Some of our children have some of the worst teeth in Europe. We need to reverse the trend.'

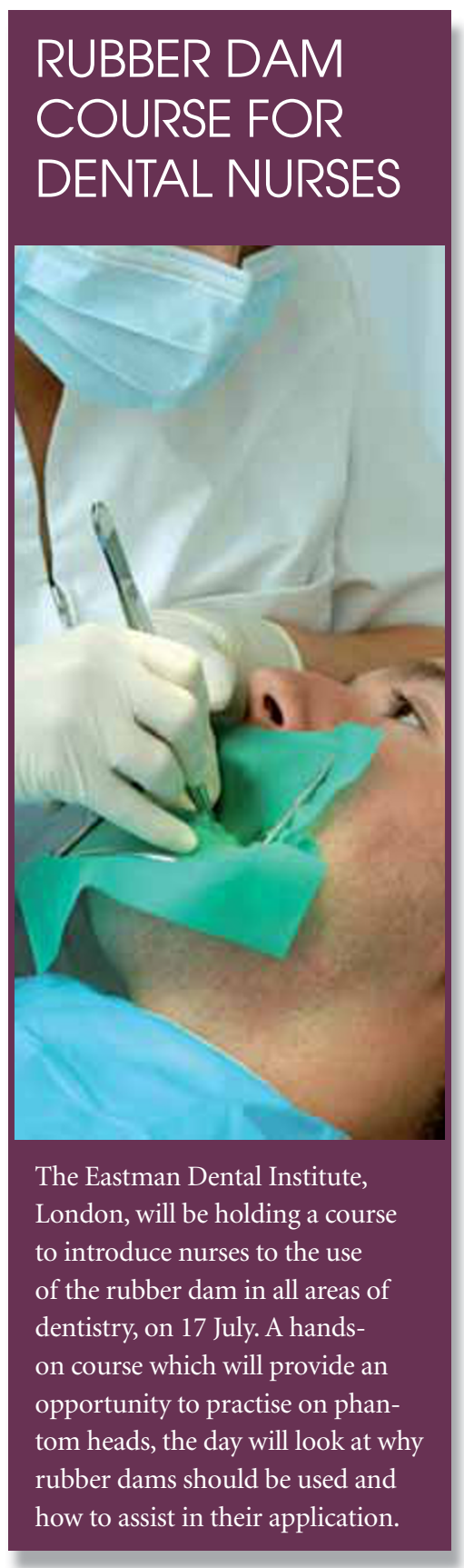

